\title{
Acute aortoiliac occlusion in a COVID-19 patient
}

\author{
๑ízzet Ustaalioğlu, ®Rohat Ak, ๑Erdal Yılmaz \\ Kartal Dr. Lütfi Kırdar City Hospital, Department of Emergency Medicine, İstanbul, Turkey
}

Cite this article as: Ustaalioğlu İ, Ak R, Yllmaz E. Acute aortoiliac occlusion in a COVID-19 patient. J Health Sci Med 2021; 4(5): 758-760.

\begin{abstract}
Although COVID-19 patients are usually seen with respiratory system symptoms, these patients may also display different symptoms. COVID-19 has been associated with a variety of prothrombotic diseases such as myocardial infarction and stroke. However, the pathogenesis of this hypercoagulation has not yet been fully clarified. In this report, we present a COVID-19 patient who admitted with the complaint of weakness in both legs and was then diagnosed with aortoiliac occlusion.
\end{abstract}

Keywords: Acute arterial thrombosis, acute limb ischemia, aortic occlusion, hypercoagulability, COVID-19

\section{INTRODUCTION}

A new type of coronavirus disease (COVID-19)which first emerged in Wuhan, China-has become a major world pandemic causing serious morbidity and mortality throughout the world (1-4). Although the relationship between severe COVID-19 infection cases and venous thromboembolism has been described in the literature $(5,6)$, few cases have been reported for arterial thrombosis (7). Here, we present a case of acute aortoiliac occlusion in a COVID-19 infected patient.

\section{CASE REPORT}

A 65-year-old male patient admitted to the emergency department with the complaint of weakness in both legs that had started three hours before. The patient, who also had heart failure and hypertension, and reported that he used enalapril $10 \mathrm{mg}$, spironolactone $25 \mathrm{mg}$, and furosemide $80 \mathrm{mg}$, daily. He reported neither previous lower limb claudication nor arterial or venous thromboembolism. The patient stated that he had visited another hospital with the complaint of a dry cough, 10 days before when his coronavirus test was found positive. He isolated himself at home and used favipiravir for 5 days $(600 \mathrm{mg}$ daily for 5 days following a single loading dose of $1600 \mathrm{mg}$ on the 1st day). Vital signs at the time of admission were recorded: fever $37.0^{\circ} \mathrm{C}$; blood pressure $165 / 77 \mathrm{mmHg}$; heart rate $65 / \mathrm{min}$; and $\mathrm{s} O 2$ at room air $93 \%$. The patient's body mass index was calculated as 22.4. A physical examination revealed bilateral acute lower limb ischemia along with tachypnea.
The electrocardiogram was normal. The coagulability workup (including aPTT, PT, INR, fibrinogen) and other laboratory results were normal, except for a C-reactive protein (CRP) level of $103 \mathrm{mg} / \mathrm{L}$ (normal range:0-5) and a D-dimer level of $860 \mathrm{ng} / \mathrm{mL}(<250 \mathrm{ng} / \mathrm{mL})$. A chest computed tomography (CT) demonstrated diffuse bilateral consolidation (Figure 1). The CT angiography showed acute thrombotic occlusion in the infrarenal aorta extending to the common iliac arteries (Figure 2). The transthoracic echocardiogram did not reveal any potential source of embolism. Anticoagulant therapy was not given to the patient before thromboembolectomy. Percutaneous mechanical thromboembolectomy was performed in the emergency operating room and significant clinical and radiological improvements were achieved. The patient was hospitalized for routine post-operative care and COVID-19 treatment. The patient was discharged on the $12^{\text {th }}$ day of hospitalization without any sequelae.

\section{DISCUSSION}

Coronavirus creates a prothrombotic condition in infected hosts. Thrombotic complications in COVID-19 patients can emerge in a variety of ways including venous thromboembolism and ischemic complications associated with thrombosis of the limb, cerebral, coronary, and visceral arteries. Findings suggest that endothelial dysfunction, inflammation, cytokine release, hypercoagulation, and hypoxia contribute to thrombosis (8). 


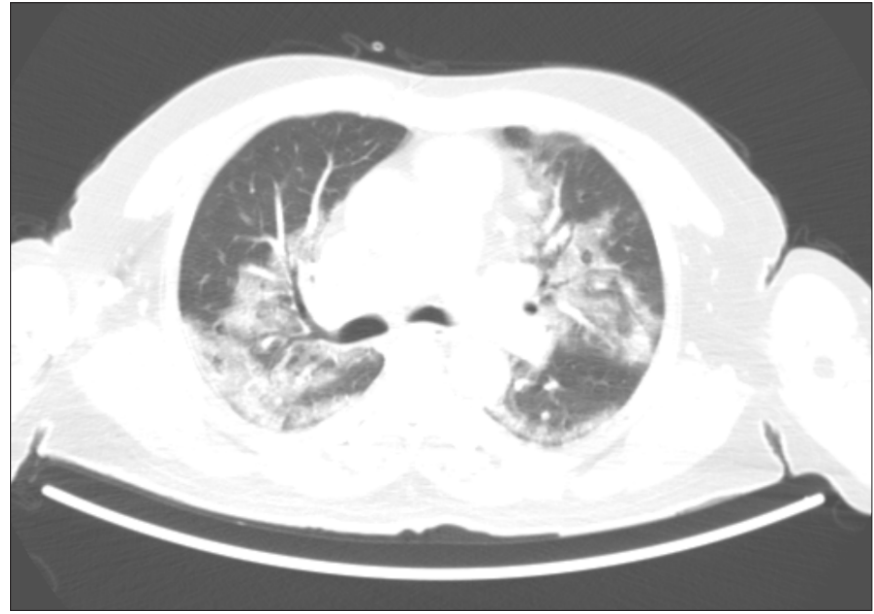

Figure 1. Chest CT scan showing pulmonary lesions typical of COVID-19.

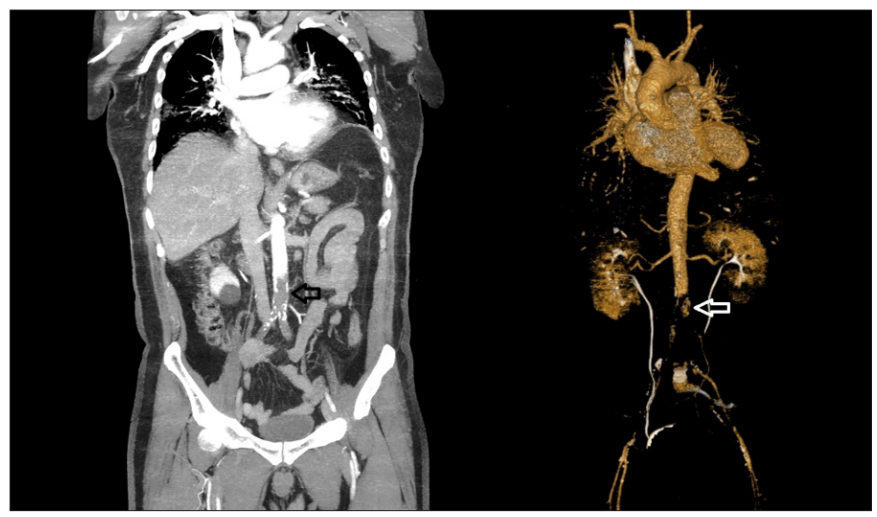

Figure 2. Infra-renal distal aortic and left iliac artery thrombotic occlusion on CT angiography, 3-dimensional reconstruction (arrows).

In the literature, as in this case, reports show a relationship between a coronavirus infection and lower limb arterial thrombosis, such as aortoiliac thrombosis. Vulliamy et al. (9) reported two patients with COVID-19 pneumonia who also had acute thrombotic occlusion of the descending aorta. Bellosta et al. (10) published a descriptive cohort study involving 20 Italian patients with acute arterial ischemia. In their study, they proposed a virus-associated hypercoagulation as a possible etiology. Klok et al. (11) reported a 31\% incidence rate of arterial or venous complications in 184 COVID-19 patients in intensive care units (ICU). In this cohort, 65 with pulmonary embolism, 3 with deep venous thrombosis, 5 with ischemic strokes, and 2 with systemic arterial thromboembolism were reported. Perini and colleagues reported 4 COVID-19 patients who had acute limb ischemia (ALI) symptoms. Two of these patients had no previously known underlying health conditions or risk factors. One of these patients was a 53-year-old male who not only showed symptoms of ALI but also signs of acute aortoiliac occlusion. This patient underwent an open thrombectomy but on the second postoperative day the patient died (12).
Prophylactic anticoagulation therapy is recommended for hospitalized patients with COVID-19 $(13,14)$. In our case study, the only treatment the patient received for the COVID-19 infection was favipiravir. However, prophylactic anticoagulants should also be given to outpatients who are elderly and have comorbidity (14).

\section{CONCLUSION}

As COVID-19 cases continue to increase globally, the number of patients with arterial thrombosis is inevitable. Since these patients are kept under strict isolation protocols, it is necessary to be vigilant towards this complication since it requires such rapid intervention. As in our case, COVID-19 patients who have arterial thrombosis could be successfully treated with anticoagulation and emergency intervention. Early recognition and intervention of ALI - which leads to a sudden reduction in limb perfusion-can help maximize the chances of limb salvage and reduce the risk of mortality among patients. When linked to COVID-19, the early recognition of this complication offers a higher probability of an improved outcome.

\section{ETHICAL DECLARATIONS}

Informed Consent: Written informed consent was obtained from all participants who participated in this study.

Referee Evaluation Process: Externally peer-reviewed.

Conflict of Interest Statement: The authors have no conflicts of interest to declare.

Financial Disclosure: The authors declared that this study has received no financial support.

Author Contributions: All of the authors declare that they have all participated in the design, execution, and analysis of the paper, and that they have approved the final version.

\section{REFERENCES}

1. Rohat AK., Doğanay F. Relationship between mean platelet volume and intensive care unit requirement in COVID-19 patients. J Health Sci Med 2021; 4: 353-7.

2. Seyhan AU, Doganay F, Yilmaz E, Topal N P, Ak R. Investigation of QT prolongation with hydroxychloroquine and azithromycin for the treatment of COVID-19. J Coll Physicians Surg Pak 2021; 30: 153-7.

3. Huang C, Wang Y, Li X, et al. Clinical features of patients infected with 2019 novel coronavirus in Wuhan, China. The lancet 2020; 395: 497-506.

4. Ak R, Kurt E, Bahadirli S. Comparison of 2 risk prediction models specific for COVID-19: the brescia-COVID respiratory severity scale versus the quick COVID-19 severity index. Disaster Med Public Health Prep 2021; 1-5. 
5. Driggin E, Madhavan MV, Bikdeli B, et al. Cardiovascular considerations for patients, health care workers, and health systems during the COVID-19 pandemic. J Am Col Cardiol 2020; 75: 2352-71.

6. Danzi GB, Loffi M, Galeazzi G, Gherbesi E. Acute pulmonary embolism and COVID-19 pneumonia: a random association? Eur Heart J 2020; 41: 1858-8.

7. Levolger S, Bokkers RP, Wille J, Kropman RH, De Vries JPP. Arterial thrombotic complications in COVID-19 patients. J Vasc Surg Cases Innov Tech 2020; 6: 454-9.

8. Varga Z, Flammer AJ, Steiger P, et al. Endothelial cell infection and endotheliitis in COVID-19. The Lancet 2020; 395: 1417-8.

9. Vulliamy P, Jacob S, Davenport RA. Acute aorto-iliac and mesenteric arterial thromboses as presenting features of COVID-19. Br J Haematol 2020; 189: 1053-4.

10. Bellosta R, Luzzani L, Natalini G, et al. Acute limb ischemia in patients with COVID-19 pneumonia. J Vasc Surg 2020; 72: 186472.

11. Klok FA, Kruip MJHA, Van der Meer NJM, et al. H. Incidence of thrombotic complications in critically ill ICU patients with COVID-19. Thromb Res 2020; 191: 145-7.

12. Perini P, Nabulsi B, Massoni CB, Azzarone M, Freyrie A. Acute limb ischaemia in two young, non-atherosclerotic patients with COVID-19. The Lancet 2020; 395: 1546.

13. Topcu AC, Ozturk-Altunyurt G, Akman D, Batirel A, Demirhan R. Acute Limb Ischemia in Hospitalized COVID-19 Patients. Ann Vasc Surg 2021; S0890-5096(21)00233-8.

14. Kollias A, Kyriakoulis KG, Dimakakos E, Poulakou G, Stergiou GS, Syrigos K. Thromboembolic risk and anticoagulant therapy in COVID-19 patients: emerging evidence and call for action. $\mathrm{Br}$ J Haematol 2020; 189: 846-7. 